\title{
Organized Symposia
}

\section{TITLE: Live Animal Carcass Ultrasound- Physical and Economic Considerations}

Organizers: Randall D. Little, Allen R. Williams, and Jayson Lusk, Mississippi State University

Moderator: Randall Little, Mississippi State University

Participants: Allen R. Williams, Mississippi State University; John Anderson, University of Kentucky; Ted Schroeder, Kansas State University; Jayson Lusk, Mississippi State University

Live animal carcass ultrasound offers beef producers a reasonable way to make relatively rapid improvement in carcass traits, central to providing an end product of consistent quality. The purpose of this organized symposium is to provide an overview of live animal carcass ultrasound, including physical and economic considerations. This interdisciplinary effort is designed to educate livestock economists and others about what live animal carcass ultrasound is and how it works, and to explore its potential economic implications. Economic implications at the cow-calf and feedlot levels of live beef production and for the beef industry in general will be discussed.

TITLE: Agricultural Commodity Organizations and Future Agricultural Policies

Organizers: Walter J. Armbruster, Farm Foundation; Louis E. Swanson, Colorado State University

Moderator: Walter J. Armbruster, Farm Foundation

Participants: Louis E. Swanson, Colorado
State University; Michelle Huffman, National Cotton Council; Chuck Lambert, National Cattlemen's Beef Association

The time is right for agricultural commodity organizations to embrace a new paradigm in which they seek opportunities to work with other interests to shape agricultural policy that serves multidimensional goals, including those of producers, consumers, environmentalists and other interested parties. There are constructive opportunities for fundamental redirection of agricultural commodity groups' policy and political foci. They will need to address most of the socioeconomic forces shaping the new agricultural political economy. This symposium examines challenges and opportunities facing those agricultural commodity organizations not normally involved in traditional commodity policy, as well as those immersed in it and the international competitive environment.

TITLE: E-Commerce in Agribusiness Curricula: How should This Be Taught?

Organizer: Allen F. Wysocki, University of Florida

Moderator: Allen F. Wysocki, University of Florida

Participants: Allen F. Wysocki, University of Florida; Timothy G. Taylor, University of Florida; Arlo Biere, Kansas State University

E-Commerce is growing at incredible speed, fundamentally altering the way the world produces, consumes, communicates, and plays. There has been an explosion of Business-to-Business and Consumer-Direct ag-related websites in the past two years. How should agribusiness educators adapt curricula 
in an effort to address the e-commerce phenomenon? Specific focus of e-commerce challenges and opportunities in agribusiness education will be presented along the following fronts: differences between e-commerce marketing and traditional marketing, selecting materials to teach e-commerce marketing skills, e-commerce as an integrated or stand-alone course, and the marketing and business strategy dimensions of e-commerce marketing.

\section{TITLE: Business Simulations in Agribusi- ness Teaching: Learning Enhancement or Playing Games?}

Organizer: Allen F. Wysocki, University of Florida

Moderator: Allen F. Wysocki, University of Florida

Participants: Allen F. Wysocki, University of Florida; Gary F. Fairchild, University of Florida; Timothy G. Taylor, University of Florida; Charlie Hall, Texas A\&M University

A discussion of the use of business simulations in agribusiness curricula. Specific focus will be given to challenges and opportunities presented by the use of simulations along the following fronts: arguments for and against simulations, selection and appropriate use of simulations tradeoffs between flexibility, manageability, and realism, implicit and explicit costs associated with utilizing simulations, and a comparison of pre-simulation expectations and objectives to post-simulation evaluation of the learning experience.

\section{TITLE: Food Assistance Needs: A Southern Perspective}

Organizers: Bo Beaulieu, Southern Rural Development Center; Lynn Reinschmiedt, Mississippi State Univeristy

Moderator: Bo Beaulieu, Southern Rural Development Center

Participants: John P. Bartkowski, Mississippi
State University; Steve H. Murdock, Texas A\&M University; Bradford Mills, Virginia Tech; Mark Henry, Clemson University

The Food Stamp Program saw an unprecedented decline in participation from 27.5 million participants in 1994 to 18.2 million participants in 1999. Debate continues over the relative contribution to this decline resulting from a strong national economy versus changes in social welfare program policies such as the 1996 Personal Responsibility and Work Opportunity Reconciliation Act. Concerns that dramatic declines in food stamp numbers have occurred in light of the fact that the program remains an entitlement for eligible families has generated concern that many former welfare families are not receiving program benefits. This symposium examines food stamp utilization patterns across the South.

\section{TITLE: The New Ag E-conomy: How New? How Different?}

Organizers: Jeffrey W. Hopkins and Mitchell Morehart, Economic Research Service, USDA

Moderator: Jeffrey W. Hopkins, Economic Research Service, USDA

Participants: Brian Buhr, University of Minnesota; Stan Ernst, Ohio State University; Steve Turner, University of Georgia

Agricultural e-commerce sites have proliferated on the internet in the past two years, and some sites have managed to attract the visits of a sizable number of farmers. We present information on the trends in adoption of computer and Internet technology as well as their management impacts on agriculture as a whole and within certain segments. Popular concerns, such as the digital divide and the impact on the structure of agriculture, will be addressed through empirical results and interpreted through economic theory. We will suggest ways to design research to inform policy and develop programming for the new agricultural e-conomy. 


\section{TITLE: Cow/Calf Record-Keeping Software Workshop}

Organizer: Damona Doye, Oklahoma State University (for Southern Extension Farm Management Committee, Farm Records Subcommittee)

Moderators: Darrh Bullock, University of Kentucky; Damona Doye, Oklahoma State University; Larry Falconer, Texas A\&M University; Gordon Groover, Virginia Tech

Participants: Larry Hafer, CowSense; Kris Ringwall, CHAPS 2000, North Dakota State University; Tim Cross and Clyde Lane, THE Beef Cattle FIRM, The University of Tennessee; Steve Johnson, CowCalf 5, University of Nebraska, Great Plains Vet Center

Farm management specialists and animal scientists are often asked by producers to recommend cow/calf record-keeping software. However, few have had the opportunity to use and compare leading packages. This session would provide the opportunity for specialists from both disciplines to gain "hands on" experience with three packages as well as discuss opportunities for cooperation in developing teaching materials and promoting and conducting workshops. Additional ideas for research and extension programs may emerge as a result of the joint session.

TITLE: Agriculture in the WTO and Former
Section 22 Protection: Freer Trade or Stumbling Block to MTN?

Organizers: C. Parr Rosson, III and Flynn J. Adcock, Taxas A\&M University

Moderator: Albert Allen, Mississippi State University

Participants: Lynn Kennedy, Louisiana State University; Won Koo, North Dakota State University; Darren Hudson, Mississippi State University; Don Ethridge, Texas Tech University; Stanley Fletcher, University of Georgia; Jose Peña, Texas Agricultural Extension Service; David Anderson, Texas A\&M University; Hal Harris, Clemson University; C. Parr Rosson, III, Texas A\&M University

The purpose of this symposium is to discuss a few of the potential difficulties confronting the current round of negotiations of the World Trade Organization (WTO) with respect to agricultural issues. The symposium is based on recent leaflets prepared by members of S-287 Southern Region Research Committee. It is designed to educate agricultural and rural leadership about key trade issues and their likely impacts to provide information and discuss crucial trade issues related to the next round of the WTO, and to discuss implications for applied research and extension education program development. 